\title{
ACOUSTIC PERFORMANCE OF GREEN POLYMER FOAM FROM RENEWABLE RESOURCES AFTER UV EXPOSURE
}

\author{
Nik Normunira Mat Hassan ${ }^{1}$ and Anika Zafiah M. Rus ${ }^{1 *}$ \\ ${ }^{1}$ Sustainable Polymer Engineering, Advance Manufacturing and Material Center \\ (AMMC), Faculty of Mechanical and Manufacturing Engineering, \\ Universiti Tun Hussein Onn Malaysia, \\ 86400 Parit Raja, Batu Pahat, Johor, Malaysia \\ *Email: zafiah@uthm.edu.my
}

\begin{abstract}
Flexible and rigid green polymers foam were prepared by the reaction of polyol based on waste vegetable oil with commercial Polymethane Polyphenyl Isocyanate (Modified Polymeric-MDI) and Diisocyanate-diphenylmethane (Abou-El-Hossein, Kadirgama, Hamdi, \& Benyounis). The effect of the Ultraviolet (Annie Paul et al.) on flexible and rigid green polymer foam was examined by Scanning Electron Microscope (SEM) and acoustic study of sound absorption coefficient (Baldoukas, Soukatzidis, \& Demosthenous). The morphology structure of rigid green polymer foam gives a close cell structure and smallest cell size with UV exposure compared with flexible green polymer foam, which gives open cell structure and largest cell size after UV exposure.The $\alpha$ of flexible green polymer foam gives better compared with the $\alpha$ of rigid green foam at low frequency level before UV exposure. The noise reduction coefficient (NRC) of flexible green polymer foam is higher, 0.2339, compared with rigid green foam which is 0.1407 . The NRC of flexible green polymer foam drops to $24.41 \%$ with exposure up to 240 hours on UV light. The UV light was influenced by the sound absorption level with lower frequency, hence less ductile characteristic of the flexible and rigid green polymer foam.
\end{abstract}

Keywords: Green polymer foam; UV light; Sound absorption coefficient.

\section{INTRODUCTION}

Polyurethane (PU) foam is a versatile engineering material, which finds a wide range of applications because of its properties, and can be readily tailored by the type and composition of its component. However, the main market for PU foam is in polymeric foam, which is flexible and rigid (Rejab et al., 2010; Shan, Ghazali, \& Idris, 2013; Verjedo et al., 2009). Flexible and rigid PU foams are two predominant application forms of PU with coatings, sealants, elastomers, and adhesives being other common forms of applications. PU foam can be produced with open-cell structure to be more flexible or a close cell structure to be more rigid. Generally, PU foam is one of the major products of urethane material. The characteristic of PU foam can be changed by adjusting the chemical composition of the raw materials, in particular polyol and isocyanate in which the PU properties mainly depend on the types of polyol such as functionality and hydroxyl value ( $\mathrm{Lim}, \mathrm{Kim}, \& \mathrm{Kim}, 2008$ ). The formation of PU foam follows the same general reaction of isocyanate with polyol shown in Figure 1, and both are derived when polymerization reactions occur similar to nearly all polymeric 
materials (Aeyzarq Muhammad Hadzreel \& Siti Rabiatull Aisha, 2013; Hardinnawirda \& SitiRabiatull Aisha, 2012; Lim et al., 2008; M. Khairul Zaimy, Zafiah, Rus, Ab Latif, \& Nurulsaidatulsyida, 2013). The preparation of PU foam is by two methods: one-shot method and two-shot method. In the one shot method of fabrication, all materials are put in a mixing cup and mixed homogeneously before they are poured into the mold. In the two-shot method, the isocyanate is added to the mixture at the second stage. According to (Abdel Hakim, Nassar, Emam, \& Sultan, 2011), the prepared formation of rigid PU foams were synthesized in the one-shot method using polyol based on sugar-cane bagasse.
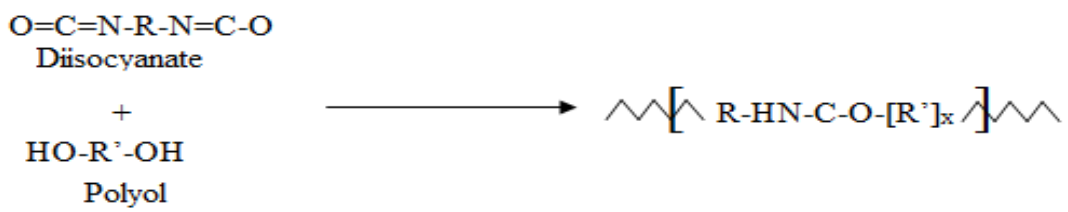

Figure 1. The general reaction of diisocyanate with polyol to form polyurethane linkages (Lim et al., 2008)

The forming process of PU foam consists of three basic stages, namely, bubble initiation, bubble growth and cell opening (Klempner \& Sendijarevic, 2004). The bubble initiation was initially introduced by physically bending air into the mixture. The bubble growth occurs when the gas diffuses and expands the gas phase due to increasing the forming temperature. The gas may originate from sources such as a gas involved in water reaction, blowing agents, carbon dioxide and surfactant. The heat generated during the reactions due to exothermic process plays an important role in expansion to form a cellular structure. The bubble continues to grow, and begins the cell opening to produce polyurethane foam. Natural vegetable oil, which was recently considered to be one of the most important classes of renewable sources, has high potential for synthesis and of becoming a new polyol source for PU. It can also be replaced for commercial polyol in manufacturing PU. Developing renewable resources such as soybean oil, canola oil, rapeseed oil, corn oil, palm oil, sunflower and linseed oil for the polymer industry has become highly desirable for both economic and environmental reasons (Rus, 2009). Successful PU elastomers synthesis using vegetable oil derived polyol revealed the improvement of thermal stability and oxidation resistance (Mohamed \& Atan, 2012; Zhang, Jeon, Malsam, Herrington, \& Christopher, 2007).

Polyol is traditionally produced from petroleum. The production of polyols from petrochemicals is costly, requires a great deal of energy, and has adverse effects on the environment. Hence, the bio-polyol from vegetable oil that is non-petroleum based, renewable, less costly, and more eco-friendly, can be applied as an alternative to reduce consuming petroleum based. The bio-polyols synthesized from vegetable oils are attractive alternatives for producing green polymer foam. Among the different natural oils, the vegetable oils from palm oil are widely explored for bio-polyol synthesis due to the main components existing in vegetable oil, triglycerides, which are available as platform chemicals for polymer synthesis. The several reactive positions of triglyceride vegetable oil are saturated and unsaturated fatty acids which are useful in many synthesis transformations and have become new polyol sources. In the polymer industry, vegetable oils, which represent a major potential source of chemicals, have been utilized as an alternative feedstock for bio-monomers (Rus, 2009; Suresh, Kong, Bouzidi, \& Sporns, 2007). PU foam is defined as acoustic material. The sound 
absorption measurement is related to the capacity of material to absorb, reflect, and dissipate acoustic energy. Sound absorption constitutes one of the major requirements for human comfort today in automobiles, manufacturing environments, and equipment generating higher sound pressure. This drives the need to develop more efficient and economical ways of producing sound absorption materials. Industrial applications of sound absorption generally include the use of materials such as glass wool, foam, mineral fibres, and their composites. For automotive industries, sound absorption is an important issue; the developed sound insulation should be efficient by means of getting the sound reduced and, economically, it is necessary to produce sound absorbing material which is cheap, user friendly, and moderate sound absorbent coefficient. The absorption is desired at lower frequencies, thickness, and weight. A sound absorber with different specific airflow resistance can be used to achieve desirable results. One method of increasing flow resistivity is the addition of a flow resistant scrim or film layer. A scrim is a fibrous cover layer with finite flow resistance, and a film is a plastic cover layer with infinite flow resistance (Zhang, Junqing, Zhen, Fenglei, \& Yudong, 2012). This paper emphasizes the effect of the Ultraviolet (Annie Paul et al.) on flexible and rigid green polymer foam using Scanning Electron Microscope (SEM) and sound absorption coefficient (Baldoukas et al.) by impedance tube test. Furthermore, it determines the morphology structure of flexible and rigid green polymer foam after UV exposure up to 240 hours. The sound absorption performance of the flexible and rigid green polymer foam was measured at low and high frequency level.

\section{METHODOLOGY}

\section{Materials}

Green bio-monomer from waste vegetable oil, Polymethane Polyphenyl Isocyanate (Modified Polymeric-MDI) (viscosity at $25^{\circ} \mathrm{C}=120-160 \mathrm{cps}$, specific gravity at $25^{\circ} \mathrm{C}$ $=1.18-1.20 \mathrm{~g} / \mathrm{ml}$, NCO Content, $\%$ wt $=26.3-27.3)$ and Polymethane Polyphenyl Isocyanate (diisocyanate-diphenylmethane (MDI) (Viscosity at $25^{\circ} \mathrm{C}=150-250 \mathrm{cps}$, Specific Gravity at $25^{\circ} \mathrm{C}=1.22-1.25 \mathrm{~g} / \mathrm{ml}$, NCO Content $=30.5-32.0 \%$ wt. .

\section{Sample Preparations}

Green bio-monomer based on waste cooking oil from Small Medium Entrepreneur (SMEs) was prepared by using in-house catalyst preparation to generate the epoxides from unsaturated fatty compound, which comprises the acid-catalyst ring opening of the epoxides to form polyols (Rus, 2008, 2009, 2010). The green monomer was mixed with Modified Polymeric-MDI and diisocyanate-diphenylmethane (Abou-El-Hossein et al.) was prepared by simple open casting method to produce the green bio-polymer foam. The mixture was poured into an open mold and allowed to rise freely and the green polymer foam was removed from the mold after 12 hours. The samples were exposed to the UV light in UV Lamp Test Chamber Model HD-703 (Haida International Equipment Co., LTD) at different exposure times at $40^{\circ} \mathrm{C}$. The UV exposure of the samples was carried out using an array of UV fluorescent lamps emitting light in the region of 280 to $320 \mathrm{~nm}$ with a tail extending to $400 \mathrm{~nm}$. 


\section{Scanning Electron Microscope}

The top surface of each green polymer foam samples was sputter coated with gold at $25 \mathrm{~mA}$ plasma current and $2 \mathrm{~Pa}$ of camber pressure to make them conducting. Cellular structure images were examined by using scanning electron microscope (SEM) of JEOL-JSM6380LA operates at $15 \mathrm{kV}$ at $30 \mathrm{X}$ magnification.

\section{Acoustic Property}

The green bio-polymer foam samples were tested by impedance tube test according to ASTM E1050 and ISO 10534-2 for horizontally mounted orientation sensitive materials for the frequency range of 100-6300 Hz. Impedance tube was used to test the sound absorption of the samples at low frequency level by using $100 \mathrm{~mm}$ sample diameter, while sound absorption at high frequency was determined by using $28 \mathrm{~mm}$ sample diameter.

\section{RESULTS AND DISCUSSION}

\section{Characteristic of green polymer foam after UV exposure}

The degradation of foam usually starts on the outer surface of the green polymer foam where it is exposed to UV light. UV degradation leads to discoloration which usually shows the reduction of property (Rus, 2009). In Figure 2, green polymer foams show yellowing on the exposed surface of UV light for sound absorption test. The green polymer foams have more yellowing after increasing the time of exposure to UV light. According to $\mathrm{Xu}$ et al. (Papuga), the UV irradiated samples of green polymer foams give less ductile due to polymer molecules in the foam break (chain-scission), crosslink or suffer substitution reaction in an aggressive environment.

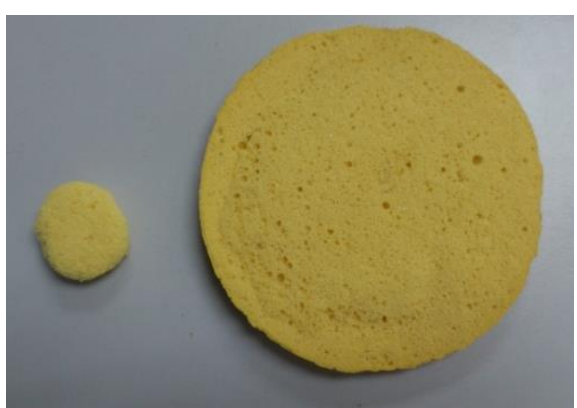

(a)

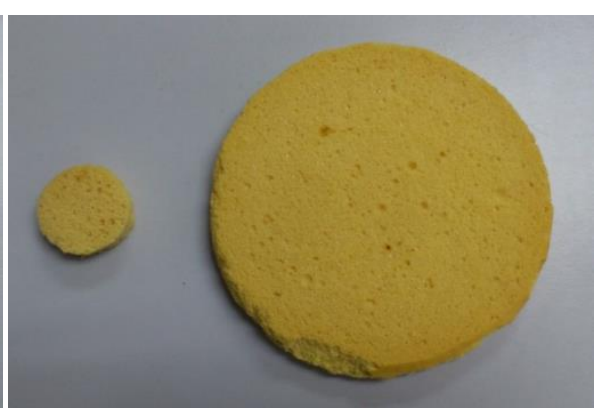

(b)

Figure 2. Yellowing of green polymer foam: (a) before UV exposure and (b) after UV exposure of acoustic sound absorption measurement sample.

\section{Morphology of green polymer foam}

The cross section surfaces of rigid green polymer foam exposed and unexposed to UV light were observed with SEM as shown in Figure 3 (a) and Figure 3 (b). The shapes of the cells are spherical and close cell structure of rigid green polymer. The cell structure is homogenous, with small struts and lamellae before exposure to UV light as shown in Figure 3 (a). However, the morphology structure after UV exposure is non-homogenous 
with small struts, as shown in Figure 3 (b). The average cell size indicates that the highest cellular cell size is $432.1 \mu \mathrm{m}$ of UV exposure; in comparison, unexposed sample to UV light is $501.5 \mu \mathrm{m}$. Additionally, Figure 3 (a) reveals that no cracks were observed on the surface of the original rigid green polymer foam before exposure to UV. Also, in Figure 3 (b), some inclined cracks occur on the rigid green polymer foam surface samples after exposure to UV for 240 hours.

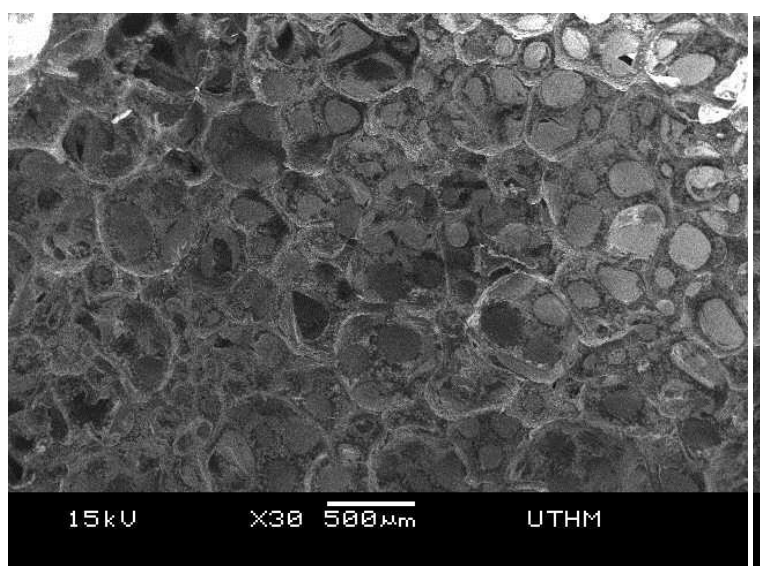

(a)

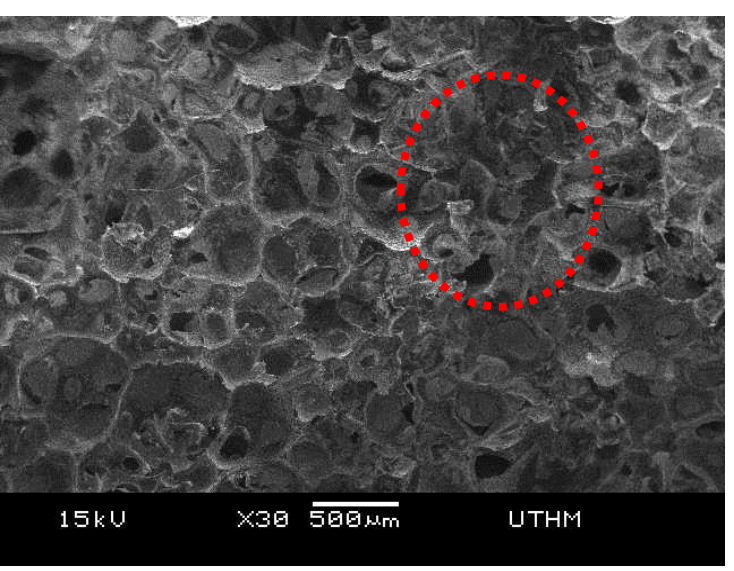

(b)

Figure 3. SEM micrograph of rigid green polymer foam: (a) before UV exposure and (b) after UV exposure with the red circle indicating crack area.

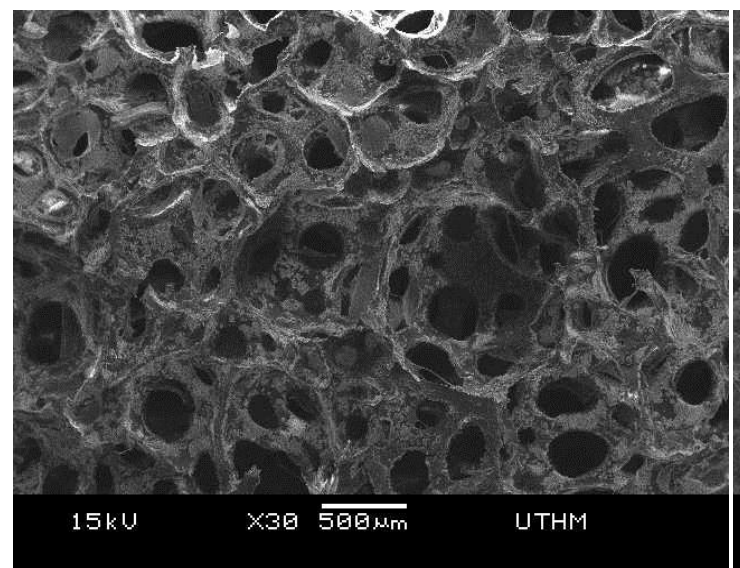

(a)

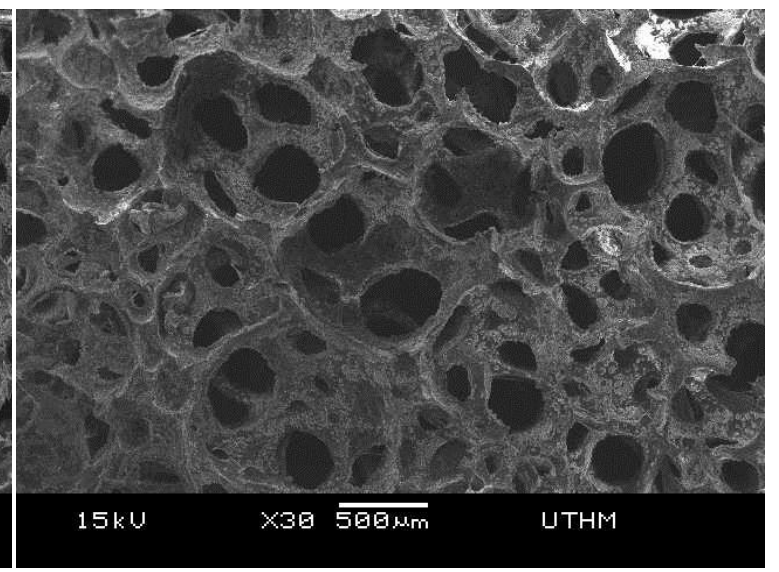

(b)

Figure 4. SEM micrograph of flexible green polymer foam: (a) before UV exposure and (b) after UV exposure.

Figure 4 shows flexible green polymer foam morphological structure with and without UV exposure of sound absorption test specimens. The flexible green polymer foam represents open-cell cellular structure and anisotropic. (Goren, Chen, Schadler, \& Ozisik, 2010)reported that almost all man-made foams are anisotropic. The open-cell structure comprises many small open windows located on the cell wall and these cause the struts formed in between the open window (Klempner \& Sendijarevic, 2004). The SEM results present the cell distribution of green polymer flexible foam without UV exposure, showing uniform pore distribution, smaller cell size, and homogeneity. The morphology of cell structure of flexible green polymer foam is identical before and after 
UV exposure. The larger cells were found with UV exposure is $604.2 \mu \mathrm{m}$ compared with the cellular structure of the flexible green polymer foam without UV exposure is $411.4 \mu \mathrm{m}$. The difference of cellular structure of both flexible green polymer foam due to the thicker struts gives the cell wall with large surface areas of the cell wall. In addition, the effect of UV exposure of green polymer foam was examined in terms of the little changes of the pore density distribution. The pore density of green polymer foam was obtained by (Kumar \& Suh, 1990) method. In this method, the number of pores was examined by counting the pore in the SEM micrographs (Kumar \& Suh, 1990). The magnification is $\mathrm{M}$, area of SEM image is $\mathrm{A}$, and $\left(n \cdot \mathrm{M}^{2} / \mathrm{A}\right)$ would give pore density per unit area and can be converted to pore density per volume, $\mathrm{N} v$ (Eq. 1).

$$
\mathrm{N} v=\left(n \cdot \mathrm{M}^{2} / \mathrm{A}\right)^{3 / 2}
$$

Table 1 shows the pore density per volume of green polymer foam in which the highest gives $68.975 \times 10^{6} \mathrm{~cm}^{-1}$ for rigid green polymer foam before UV exposure. The $\mathrm{N} v$ was decreased during UV exposure down to $59.787 \times 10^{6} \mathrm{~cm}^{-1}$ of rigid green polymer foam. (Goren et al., 2010) investigated the pore density of foam provided by Eq. 1 based on the final foamed volume and not on the initial volume of the sample, influenced by filler sizes and filler surface.

Table 1. Number, diameter, and pore density per volume of green polymer foam.

\begin{tabular}{lcccc}
\hline Sample & $\begin{array}{c}\text { Rigid green } \\
\text { polymer } \\
\text { foam }\end{array}$ & $\begin{array}{c}\text { Rigid green } \\
\text { polymer foam of } \\
\text { UV exposure }\end{array}$ & $\begin{array}{c}\text { Flexible green } \\
\text { polymer foam }\end{array}$ & $\begin{array}{c}\text { Flexible green } \\
\text { polymer foam of } \\
\text { UV exposure }\end{array}$ \\
\hline $\begin{array}{l}\text { Number of } \\
\text { pore }\end{array}$ & 22 & 20 & 15 & 12 \\
$\begin{array}{l}\text { Diameter } \\
\text { pore }(\mu \mathrm{m})\end{array}$ & 501.5 & 432.1 & 411.4 & 604.2 \\
$\mathrm{Nv} \quad\left(10^{6}\right)$ & 68.975 & 59.787 & 38.833 & 27.786 \\
$\mathrm{~cm}^{-1}$ & & & & \\
\hline
\end{tabular}

\section{Sound Absorption Coefficient}

The normal incident sound absorption coefficient (Baldoukas et al.) of rigid green polymer foam was determined as a function of the sound frequency as shown in Figure 5. The plotted curves combine the measured data in the low frequency range of 100$1600 \mathrm{~Hz}$, where human sensitivity to noise is high and the measured data at high frequency range is up to $6300 \mathrm{~Hz}$ to indicate a whole bandwidth of the $1 / 3$ octave band frequency (Jiang et al., 2009). The $\alpha$ is defined as the ratio of the acoustic energy absorbed by the green polymer foam ( $\left.\mathrm{I}_{\text {incident }}-\mathrm{I}_{\text {reflection }}\right)$ to the acoustic incident ( $\left.\mathrm{I}_{\text {incident }}\right)$ on the surface foam and is dependent on frequency range (Verjedo et al., 2009). The absorption coefficient was calculated based on the average value of foam at $28 \mathrm{~mm}$ diameter and $100 \mathrm{~mm}$ diameter of samples, $10 \mathrm{~mm}$ thick at frequency range from 100$6300 \mathrm{~Hz}$. Figure 5 shows the acoustic absorption coefficient of the rigid green polymer foam with and without UV exposure. Rigid green polymer foam with UV exposure gives maximum $\alpha$ of 1 at medium frequency compared with rigid green polymer foam without UV exposure. The ability of rigid green polymer foam of UV exposure to absorb noise is the highest at $3600 \mathrm{~Hz}$ in which $\alpha$ is approximately equal to 1 . This indicates that sound waves were absorbed when the coefficient reached a value of 1 
(Parikh, Chen, \& Sun, 2006). However, the peak of rigid green polymer foam without UV exposure gives the highest $\alpha$ at $2800 \mathrm{~Hz}$, which is 0.91 . Hence, at low frequency range, the rigid green polymer foam without UV exposure is better compared with UV exposure. This behaviour occured due to the effect of UV exposure on the morphology cell structure characteristic in which the cell size was decreased as tabulated in Table 1.

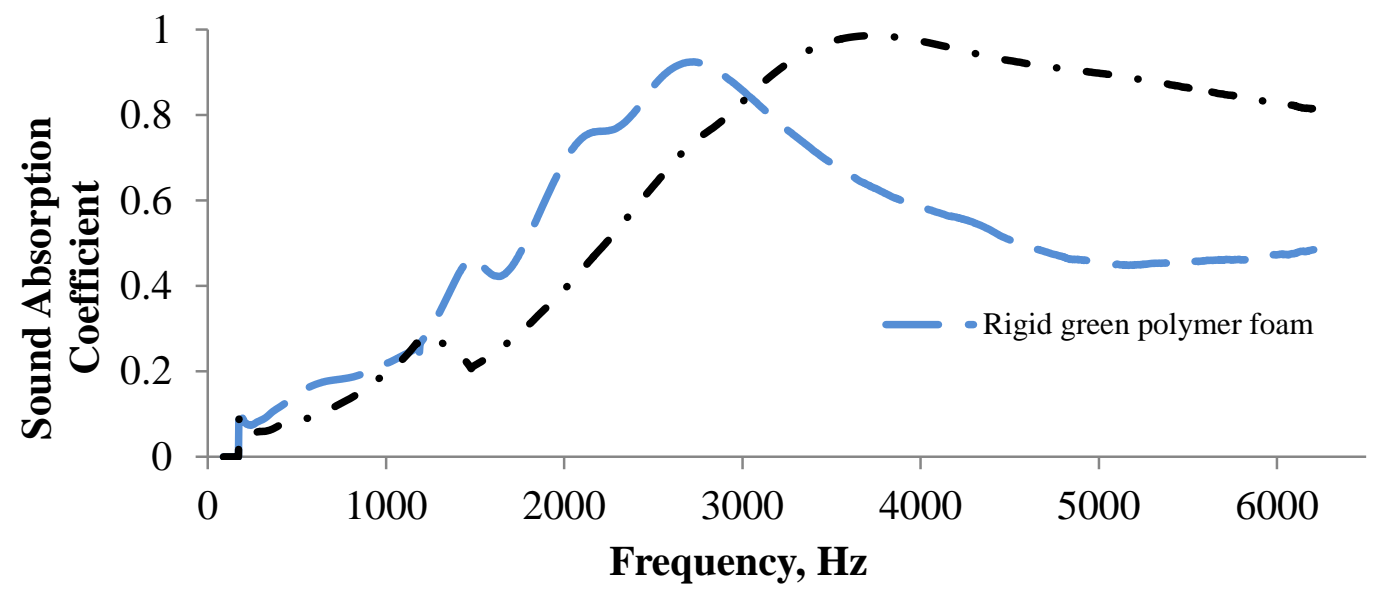

Figure 5. Absorption coefficient (Baldoukas et al.) of rigid green polymer foams with and without UV exposure.

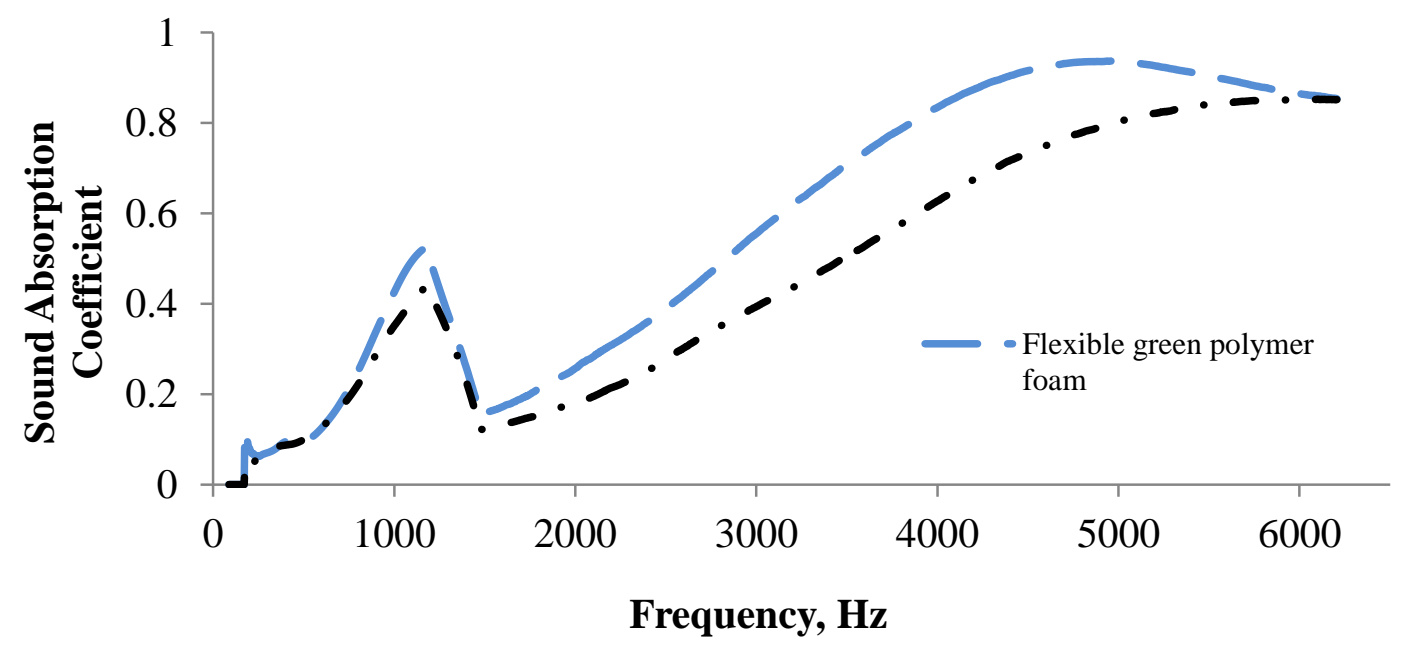

Figure 6. Absorption coefficient (Baldoukas et al.) of flexible green polymer foams with and without UV exposure.

The sound absorption property of flexible green polymer foam with and without UV exposure was analyzed based on Figure 6. At low frequency range, it is observed that the flexible green polymer foam without UV exposure gives the highest $\alpha$ compared with the UV exposure sample. The maximum $\alpha, 0.54$, at the lower level frequency at $1280 \mathrm{~Hz}$, indicated that only $54 \%$ of the incident sound waves were absorbed by the noise absorbing material. However, the $\alpha$ decreases by $18.5 \%$ at the low frequency level of UV exposure sample due to the larger size of porous cell, thus reducing the absorption coefficient at low frequency level (Crocker \& Jorge, 2010). At higher frequency level, $\alpha$ is approximately equal to 1 at $4500 \mathrm{~Hz}$ without UV exposure, while the $\alpha$ drops to 0.84 at the same frequency level after UV exposure. The $\alpha$ of flexible 
green polymer foam before UV exposure is better compared with after UV exposure at the whole frequency level. The decreasing of $\alpha$ was related to the increasing size of cell structure based on SEM morphology, thus influencing the sound absorption performance. According to (Verjedo et al., 2009), the sound absorption characteristic was improved by decreasing the cell size and increasing the tortuosity of the foam.

\section{Noise Reduction Coefficient}

In order to analyse the effect of UV exposure to acoustic property of rigid and flexible green polymer foam, the noise reduction coefficient (NRC) was calculated according to eq. (2) using the average value of $\alpha$ obtained in sound absorption test (Borlea, Rusu, Ionescu, \& Ionescu, 2011). This equation is used to determine the noise reduction coefficient at lower frequency, which is $250-2000 \mathrm{~Hz}$, but not at high frequency.

$$
\mathrm{NRC}=\left[\left(\alpha_{100}+\alpha_{200}+\alpha_{1000}+\alpha_{2000}\right) / 4\right]
$$

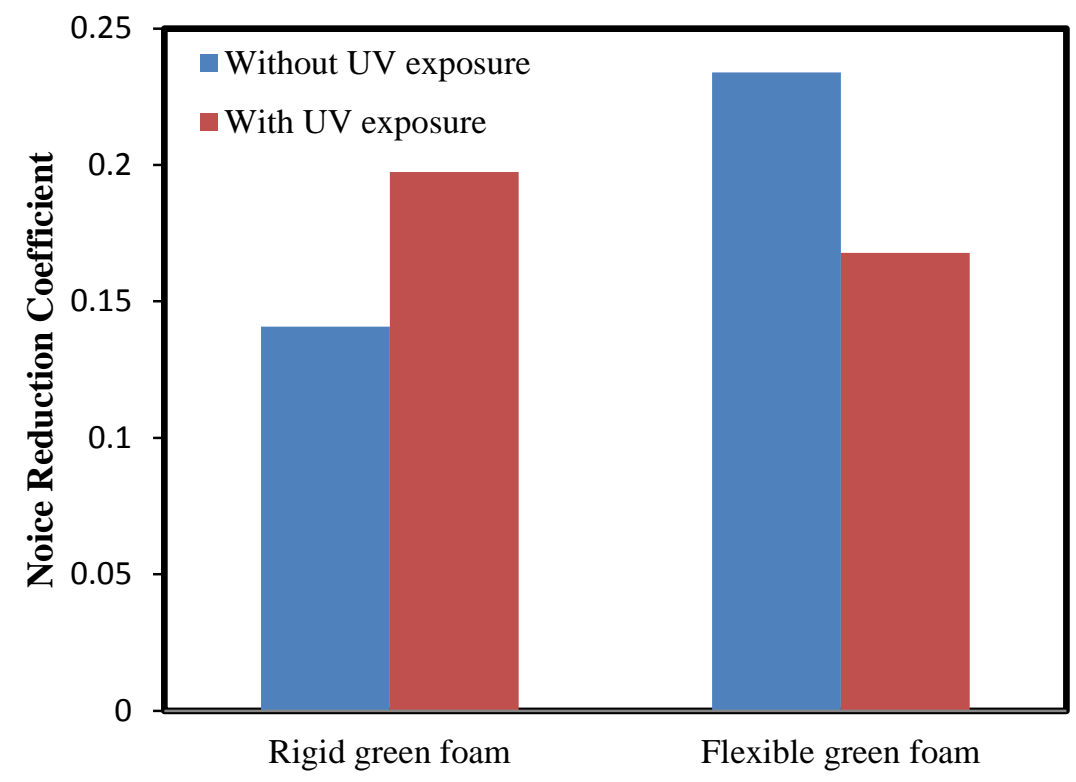

Figure 7. Noise reduction coefficient (NRC) of rigid and flexible green polymer foams with and without UV exposure.

The NRC represents the amount of sound energy absorbed upon striking a particular surface of green polymer foam. Figure 7 shows the variation which occurs in NRC of exposed and unexposed green polymer foam. The NRC of rigid green polymer foam gives the lowest value of 0.1407 , but this increased after UV exposure to 0.1974. However, the NRC of flexible green polymer foam, which increased with UV exposure, is 0.2339 ; this is compared with 0.1786 before UV exposure. The NRC value is often useful in the determination of the applicability of a material to a particular situation. However, where low or very high frequencies are involved, it is usually better to consider sound absorption coefficient instead of NRC data. 


\section{CONCLUSIONS}

The polyol based on waste vegetable oil could be used as one of the raw materials for preparation of green polymer foam. The morphology structure of rigid green polymer foam exhibited reduction in close cell structure size with UV exposure compared with flexible green polymer foam of open cell structure and increased cell size after UV exposure. In addition, the cell size diameter of green polymer foam influences by increasing the exposure time of UV light, while it decreased the sound absorption at low frequency level, hence less ductility of green polymer foam property.

\section{ACKNOWLEDGMENT}

The author would like to thank the Malaysian Government and University Tun Hussein Onn Malaysia (UTHM), Johor and Malaysian Technical University Center of Excellence (MTUN CoE) for supporting this research study under research grant Vot C014 and C015.

\section{REFERENCES}

Abdel Hakim, A. A., Nassar, M., Emam, A., \& Sultan, M. (2011). Preparation and characterization of rigid polyurethane foam prepared from sugar-cane bagasse polyol. Material Chemistry and Physics, 129, 301-307.

Abou-El-Hossein, K. A., Kadirgama, K., Hamdi, M., \& Benyounis, K. Y. (2007). Prediction of cutting force in end-milling operation of modified aisi p20 tool steel. Journal of Materials Processing Technology, 182(1-3), 241-247.

Aeyzarq Muhammad Hadzreel, M. R., \& Siti Rabiatull Aisha, I. (2013). Effect of reinforcement alignment on the properties of polymer matrix composite. Journal of Mechanical Engineering and Sciences, 4, 548-554.

Annie Paul, S., Boudenne, A., Ibos, L., Candau, Y., Joseph, K., \& Thomas, S. (2008). Effect of fiber loading and chemical treatments on thermophysical properties of banana fiber/polypropylene commingled composite materials. Composites Part A: Applied Science and Manufacturing, 39(9), 1582-1588.

Baldoukas, A., Soukatzidis, F., \& Demosthenous, G. (2008). Experimental investigation of the effect of cutting depth, tool rake angle and workpiece material type on the main cutting force during a turning process. Paper presented at the Proceedings of the 3rd International Conference on Manufacturing Engineering (ICMEN), Greece.

Borlea, A., Rusu, T., Ionescu, S. M., \& Ionescu, A. (2011). Acoustical materials-sound absorbing materials made of pine sawdust. Romanian Journal of Acoustical and Vibration, 8(2), 95-98.

Crocker, M. J., \& Jorge, P. A. (2010). Recent trends in porous sound-absorbing materials. Sound and Vibration, 12-17.

Goren, K., Chen, L., Schadler, L. S., \& Ozisik, R. (2010). Influences of nanoparticle surface chemistry and size supercritical carbon dioxide processed nanocomposite foam morphology. The Journal of Supercritical Fluids, 51, 420427.

Hardinnawirda, K., \& SitiRabiatull Aisha, I. (2012). Effect of rice husks as filler in polymer matrix composites. Journal of Mechanical Engineering and Sciences, 2, 181-186. 
Klempner, D., \& Sendijarevic, V. (2004). Polymeric foams and foam technology: 2nd Edition, Munich: Hanser.

Kumar, V., \& Suh, N. P. (1990). A process for making microcellular thermoplastic part. Polymer Engineering Science, 30, 1323-1329.

Lim, H., Kim, S. H., \& Kim, B. K. (2008). Effect of silicon surfactanct in rigid polyurethane doams. eXPRESS Polymer Letter, 2, 194-200.

M. Khairul Zaimy, A. G., Zafiah, A., Rus, M., Ab Latif, N., \& Nurulsaidatulsyida, S. (2013). Mechanical and thermal properties of waste bio-polymer compound by hot compression molding technique. Journal of Mechanical Engineering and Sciences, 5, 582-591.

Mohamed, W. A. N. W., \& Atan, R. (2012). Polymer electrolyte membrane fuel cell. International Journal of Automotive and Mechanical Engineering, 5, 648-659.

Papuga, J. (2011). A survey on evaluating the fatigue limit under multiaxial loading. International Journal of Fatigue, 33, 153-165.

Parikh, D. V., Chen, Y., \& Sun, L. (2006). Reducing automotive interior noise with natural fiber nonwoven floor covering system. Textile Research Journal, 76, 813-820.

Rejab, M. R. M., Sani, M. S. M., Noor, M. M., Kadirgama, K., Rahman, M. M., \& Alias, A. (2010). Mechanical behaviour of polymeric foam core at various orientation angles WIT Transactions on the Built Environment, 112, 429-438.

Rus, A. Z. M. (2008). Degradation studies of polyurethanes based on vegetable oils. (part i). . Prog in Reaction Kinetic and Mechanism, Science Reviews, 33, 363391.

Rus, A. Z. M. (2009). Material properties of novelty polyurethane based on vegetable oils. Paper presented at the The 11th International Conference on QiR (Quality in Research), Depok, Indonesia.

Rus, A. Z. M. (2010). Polymer from renewable materials. Science Polymer, 93(3), 1611.

Shan, C. W., Ghazali, M. I., \& Idris, M. I. (2013). Improved vibration characteristics of flexible polyurethane foam via composite formation. International Journal of Automotive and Mechanical Engineering, 7, 1031-1042.

Suresh, S. N., Kong, X., Bouzidi, L., \& Sporns, P. (2007). Physical properties of polyurethanes produced from polyols from seed oils: Ii. Foams. Journal of the American Oil Chemists' Society, 84, 65-72.

Verjedo, R., Stampfli, R., Alvarez-Lainez, M., Mourad, S. R.-P., M.A , Bruhwiler, P. A., \& Shaffer, M. (2009). Enhanced acoustic damping in flexible polyurethane foam filled with carbon nanotubes. . Composites Science and Technology, 69, 1564-1569.

Zhang, C., Junqing, L., Zhen, H., Fenglei, Z., \& Yudong, H. (2012). Correlation between the acoustic and porous cell morphology of polyurethane foam: Effect of interconnected porosity. Material and Design, 41, 319-325.

Zhang, L., Jeon, H. K., Malsam, J., Herrington, R., \& Christopher, W. M. (2007). Substituting soybean oil-based polyol into polyurethane flexible foam. Polymer Engineering Science, 48, 6656-6667. 